\title{
Creationism in Germany and its Possible Cause
}

\author{
U. Kutschera
}

Published online: 20 November 2007

(C) Springer Science + Business Media, LLC 2007

\begin{abstract}
In a widely cited essay published in the journal Science (Aug. 2006), it was stated that in Germany a large majority of adults are convinced of evolution. Based on a new poll, I document that this conclusion is questionable. In Sept. 2005, 60.9\% of the German population accepted naturalistic evolution, whereas $37.7 \%$ were creationists or adherents of intelligent design. Because among Christians of both confessions the percentage of anti-evolutionists is much larger than among atheists, I suggest that religious indoctrination of children may in part be responsible for the rejection of the concept of evolution, notably in the western part of Germany.
\end{abstract}

Keywords Creationism · Intelligent design ·

Religious indoctrination

\section{Introduction}

In May 1954, the German/American evolutionist Ernst Mayr (1904-2005), who was one of the major architects of the synthetic theory of biological evolution (Kutschera and Niklas, 2004), visited his home country for the first time after the end of World War II. In his unpublished Travel Notes, Mayr wrote down the following statement: "In Germany-now a clerical state - the anti-evo[lution] movement is particularly strong ... Just like McCarthy synonymizes liberalism and communism, thus after the war evolution was synonymized with the most typological

\section{U. Kutschera $(\square)$}

Institute of Biology, University of Kassel,

Heinrich-Plett-Strasse 40,

34109 Kassel, Germany

e-mail: kut@uni-kassel.de selectionism, and biology with Nazi racism" (E. Mayr, pers. comm.). In this contribution, I present new data on anti-evolutionism in Germany, which document that the situation has not changed much over the past 50 years - at least in the western part of this country.

In their article "Public acceptance of evolution", Miller et al. (2006) report that U.S. adults have been asked whether the statement, "Human beings ... developed from earlier species of animals", is true or false, or whether the respondent is not sure or does not know. The acceptance of human evolution was found to be much lower in the United States than in European countries. According to the authors, in Germany and comparable countries a large majority of adults were convinced of evolution. Here I show that this general conclusion is too optimistic.

\section{Methods and Sample Size}

Two years ago, a new poll was carried out in Germany that provided a very detailed picture of the situation in one country of Central Europe. In this representative "forsafowid-Umfrage", a special inquiry sponsored by the Giordano-Bruno-Stiftung (Mastershausen, Germany), the public's view on evolution in general, with no reference to humans, was investigated. The total number of respondents (n) was 1,520 (age 14 to 94 years; the unpublished data of Sept. 2005 were reanalyzed in June 2007 and are presented below).

Three statements were read to the respondents, who had to select that one which most closely reflected his (or her) own conviction:

1. God created all forms of life directly, as described in the Bible (creationism, CR); 
2. Life on Earth was created by a supernatural being (or God) and thereafter developed over a long period of time. This process was guided by a higher intelligence (or God) (intelligent design, ID);

3. Life on Earth evolved without the interference of God (or a higher being) by natural processes (naturalistic evolution, NE).

\section{Results and Discussion}

The general results of this poll were as follows:

1. Creationism $(\mathrm{CR})=12.5 \%$;

2. Intelligent design (ID) $=25.2 \%$;

3. Naturalistic evolution $(\mathrm{NE})=60.9 \%$; no opinion $=1.4 \%$, respectively $(n=1,520)$.

Members of both the great confessions in Germany (Catholic and Protestant, c) were much stronger adherents of creationist dogmas than those respondents without a religious confession (agnostics and atheists, a). c/a: $\mathrm{CR}=$ $14.2 / 3.3 \%$; ID $=29.5 / 8.8 \%$; $\mathrm{NE}=55.0 / 86.7 \%$; no opinion $=$ $1.3 / 1.2 \%$, respectively $(n=1,004 / 481 ; 35$ participants were adherents of other religions).

Inhabitants of the old (western, w) and new (eastern, e) Federal States (Bundesländer) responded differently. w/e: $\mathrm{CR}=13.4 / 7.7 \%$; $\mathrm{ID}=29.0 / 8.8 \%$; $\mathrm{NE}=56.1 / 81.8 \%$; no opinion $=1.5 / 1.7 \%$, respectively $(n=1,235 / 285)$.

Finally, between women (w) and men (m) statistically significant differences were found. $\mathrm{w} / \mathrm{m}: \mathrm{CR}=13.3 / 11.4 \%$; $\mathrm{ID}=31.0 / 19.1 \%$; $\mathrm{NE}=54.3 / 68.0 \%$; no opinion $=1.4 / 1.5 \%$, respectively $(n=782 / 738)$.

These results show that the majority of the German population (60.9\%) accepts naturalistic evolution, whereas $37.7 \%$ are creationists or adherents of ID. Among Christians of both great confessions, the percentage of creationists and IDers is much larger than among persons without religious belief. However, the differences between those living in the western/eastern part of Germany are striking: creationism and ID is unpopular in the former atheistic (communist) "Eastern region" (16.5\%), where solid statesponsored science education was part of the ideological struggle with the western world. In the states of the old West Germany, however, where Christian churches teach their religion in public schools, creationists plus adherents of ID constitute a large percentage of the population $(42.4 \%)$.

These data suggest that religious indoctrination of children at home and in schools may to some extent be responsible for the nonnaturalistic world view of many adult Germans. In our country, juveniles are exposed to the Biblical myth of Adam and Eve in the Kindergarden and in elementary school. Science education, however, starts much later and evolutionary biology, with a strong focus on Darwin's life and work, is taught only briefly in high school classes. Our modern view of evolutionary biology as an integrative branch of the natural sciences (Kutschera and Niklas 2004) is largely ignored.

These facts suggest that anti-evolutionism may be regarded as a kind of "faith-system", soaked up by youthful brains, that is difficult to overcome by later science education. This conclusion is supported by a 2006 poll that has shown that about $8 \%$ of biology students who want to become school teachers are adherents of young-Earth creationism ( $n=721$, western Germany; unpublished data of D. Graf, University of Dortmund). From a historical point of view it is evident that, at least in the United States, the real cause of creationism is not Christianity but fundamentalism (i.e., commitment to strict literal inerrant interpretation of a holy text such as the Bible). However, Christian fundamentalists currently represent less than $3 \%$ of the German population. Hence, fundamentalism may only in part be responsible for the spread of anti-evolutionism in Germany.

The reason why more women are adherents of ID than men is unknown. This fact is in accordance with the general finding that German women hold much stronger believes in nonscientific (esoteric) medical treatments, such as homeopathy or spiritual healing, than men. Psychologists may find an explanation that is possibly related to the evolutionary history of our species.

Finally, it should be noted that virtually every evolution/ creationism survey uses problematic questions, and this must be taken into account when interpreting such results. The biggest problem is that the science and religion issues are always mixed together into the same questions, thus forcing survey respondents into artificial choices. This is the case with questions discussed here, e.g., there is no room for "I am a theist and I believe God guides everything, but I see no conflict between this idea and the standard scientific view that the origin and evolution of life were natural processes". This group, which represents a very real position, is forced into an artificial choice between "ID" and "naturalistic evolution" in the survey questions discussed here.

In spite of these shortcomings, our novel data shed new light on the possible cause of anti-evolutionism in Europe (Kutschera 2003) and in the United States. According to Branch (2004), the belief that "evolution is well-supported by empirical evidence" is strongest "among those (US citizens) with the most education ...who seldom attend church" and weakest "among those with the least education ..., frequent church attendees ... and Republicans". These conclusions are largely in accordance with the results presented here. 


\section{References}

Branch G. The latest polls on creationism and evolution. Reports of the National Center for Science Education 2004;24:9-11.

Kutschera U. Darwinism and intelligent design: the new antievolutionism spreads in Europe. Reports of the National Center for Science Education 2003;23:17-8.
Kutschera U, Niklas KJ. The modern theory of biological evolution: an expanded synthesis. Naturwissenschaften 2004;91:255-76.

Miller DJ, Scott EC, Okamoto S. Public acceptance of evolution. Science 2006;313:765-6.

U. Kutschera is professor of physiology and evolutionary biology at the University of Kassel, Germany. 